\title{
多维发展导向视角下江苏省县域生态效率差异化评价
}

\author{
蓝以信 ${ }^{1, *}$, 张 庆 $^{1}$, 李 婵 $^{2}$ \\ 1 福州大学经济与管理学院, 福州 350116 \\ 2 福建农林大学公共管理学院, 福州 350002
}

摘要: 提高生态效率是实现县域经济绿色发展的重要方式,在充分考虑江苏省县域经济发展合作共赢以及发展导向差异的前提 下, 遴选一产、二产、三产的增加值为关键指标并设置了 3 种不同的县域经济发展导向,采用权重约束的仁慈型交叉效率模型和 Malmquist 生产率指数测算了 2015-2017 年间江苏省 32 个县域在 3 种发展导向下的生态效率和生态全要素生产率,剖析各县 域生态效率的差异性及其全要素生产率变动的驱动力,探寻各县域的差异化绿色发展模式。研究结果显示: (1) 整体上看, 江 苏省县域总体生态效率水平较高, 但同一地级市下辖的县域生态效率排名差距较大,且生态效率高的县域辐射效应不足。(2) 从不同发展导向来看,县域平均生态效率值在绿色经济导向下最高,乡村振兴导向下次之,新型工业导向下最低; 同时,同一县 域在不同导向下的生态效率排名差异较大,隶属于乡村振兴类的县域最多,绿色经济类次之, 新型工业类最少。(3) 从动态分 析来看, 江苏省县域生态效率逐步提升, 技术进步指数的增长是促进江苏省县域生态全要素生产率指数增长的主导因素, 而绝 大多数县域的技术效率变化指数保持不变或呈现衰退现象, 表明分析期内江苏省县域生态技术效率未有所提升。

关键词:县域生态效率; 差异化评价; 交叉效率; Malmquist 指数; 多维发展导向

\section{Differential evaluation of county eco-efficiency in Jiangsu Province from the perspective of multi-dimensional development orientation}

\author{
LAN Yixin ${ }^{1, *}$, ZHANG Qing ${ }^{1}$, LI Chan ${ }^{2}$ \\ 1 School of Economics and Management, Fuzhou University, Fuzhou 350116, China \\ 2 College of Public Administration, Fujian Agriculture and Forestry University, Fuzhou 350002, China
}

\begin{abstract}
Improving eco-efficiency is an important way to achieve green development in counties. In this paper, firstly, we considered the win- win cooperation of county economic development and the difference in development orientation in Jiangsu Province. Secondly, the added values of primary, secondary and tertiary industries were selected as the key indexes to set up three different county economic development orientations. Thirdly, by using the improved benevolent crossefficiency model and the Malmquist productivity index, the eco-efficiency and total ecological factor productivity of 32 counties in Jiangsu Province between 2015 and 2017 were measured under three development orientations. Finally, the difference of ecological efficiency and the driving force of total factor productivity change in different counties were analyzed, and a green development model that could take the advantages of each county was explored. The results show that: (1) on the whole, the level of ecological efficiency of counties in Jiangsu Province is high, but there is a big gap in the ranking of ecological efficiency of counties under the jurisdiction of the same prefecture- level city, and the radiation effect of counties with high ecological efficiency is insufficient. (2) From the perspective of different development

基金项目:国家自然科学基金资助项目(71701050, 71804024); 福建省社科研究基地重大研究项目( FJ2020MJDZ016); 福州大学”旗山学者”计 划项目 (GXRC201807)

收稿日期: 2020-05-25; 网络出版日期: 2021-07-24

* 通讯作者 Corresponding author.E-mail: lyx2013@fzu.edu.cn
\end{abstract}


orientations, the average eco-efficiency value of the county is the highest under the green economy orientation, the next is under the rural revitalization orientation, and the lowest is under the new industry orientation. At the same time, the ecoefficiency ranking of the same county varies greatly under different orientations, with most counties belonging to the rural revitalization category, followed by the green economy category, and the new industry category being the least. (3) From the perspective of dynamic analysis, the county ecological efficiency in Jiangsu Province has been gradually improved. Technological change is the main driving force for the growth of ecological efficiency in Jiangsu Province, while technical efficiency change is the key factor restricting its development. The technical efficiency change indexes of most counties remain unchanged or show a declining tendency, indicating that the ecological technical efficiency of the counties in Jiangsu Province has not improved shortly.

Key Words : county ecological efficiency; differential evaluation; cross efficiency; Malmquist index; multi-dimensional development orientation

当前,我国已处于生态文明建设的新时期 ${ }^{[1]}$, 面对经济和社会发展所带来的生态环境方面的严峻挑战, 党的十九大报告明确指出 “建设生态文明是中国永续发展的千年大计”,将生态文明提升到了前所未有的高 度。在此背景下,已有学者指出有效建设生态文明的关键在于生态效率的提升 ${ }^{[2]}$ 。县域作为相对独立的基 本单元, 是整个国家的根基, 其生态效率的提升是推动地区和全国生态文明建设的关键。由于我国各县域经 济在发展导向上存在较大的差异, 且县域对于资金、人才的吸引力远不如大城市, 导致当前部分县域仍存在经 济发展和绿色发展的动力不足等问题。从而如何科学合理地推进生态文明建设, 促使各县域能够走上适合自 身发展导向的差异化的绿色发展道路,已成为各县域乃至我国经济高质量发展过程中迫切需要解决的问题。 因此, 针对不同发展导向下各类县域的生态效率实施差异化评价, 探寻适合各县域的差异化绿色发展道路, 对 推动区域经济发展及我国的生态文明建设都具有重要的理论与现实意义。

目前,生态效率的研究已受到越来越多学者的关注。已有研究指出生态效率应兼顾经济、社会、生态三方 面的效益 ${ }^{[3]}$, 其核心是用最小的资源投人和生态环境影响来获得最大的社会经济产出。现有的生态效率的 测算方法主要有比值法、指标体系法和模型法 ${ }^{[4]}$ 。比值法虽然简单、易理解, 但利用少数且不同量纲的指标 通过比值形式衡量生态效率并不全面; 指标体系法虽然能综合反映不同地区的发展状况和协调程度, 但在加 权过程中极易受到主观因素的影响; 而模型法中的 DEA 方法能够有效评价多输人、多产出的同类决策单元 (DMU, Decision Making Unit), 同时很大程度上能避免受主观因素的影响, 尤其是对于研究具有许多非期望产

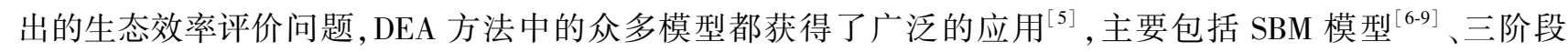
DEA 模型 ${ }^{[10-12]}$ 、交叉效率模型 ${ }^{[13-14]}$ 等。

当前, 关于生态效率的应用研究主要集中在产业层面和企业层面。例如, Liu 等 ${ }^{[15]}$ 通过能值分析方法将 生态效率评价中的社会经济系统和生态系统联系在一起, 并利用基于 SBM 的非期望产出模型对我国最大的 山西省煤矿区进行生态效率评估,但未对分析期内效率变动的原因进行探索; Fan 等 ${ }^{[16]}$ 在考虑了资源、环境、 经济三方面指标的基础上,利用 DEA 和 Malmquist 指数对中国 40 个工业园区的生态效率及其变动进行了分 析, 但该研究并未涉及对全要素生产率指数的分解及其变动机制的探讨; Charmondusit 等 $^{[17]}$ 提出将企业社会 责任作为衡量企业生态效率的一级指标, 以木制玩具业为例进行生态效率测度, 但在企业的非期望产出中只 局限于垃圾产出量; Stepien 等 ${ }^{[18]}$ 评估波兰小规模农场的生态效率, 他们的研究在产出方面考虑了耕地覆盖 率、土壤平衡指数等环境公益性指标, 能够较好地反映该问题的特殊之处。同时,对城市或区域的生态效率研 究也受到越来越多学者们的青睐。例如, 任宇飞等 ${ }^{[19]}$ 分析中国东部沿海地区四大城市群生态效率时, 为丰富 期望产出指标, 在 GDP 的基础上增加了财政收人、工业总产值两个期望产出; 黄和平等 ${ }^{[20]}$ 在研究城市工业用 地生态效率时, 在期望产出中同时考虑了经济、社会、生态三方面的效益; 马勇等 ${ }^{[21]}$ 将长江中游城市群的生态 
效率研究深化到县域尺度,但在非期望产出中只选取了空气污染指标; 常新锋和管金跧 ${ }^{[22]}$ 基于新型城镇化水平 构建产出指标体系, 弥补了单一产出设定的不足; Bian 等 ${ }^{[23]}$ 将人类福利纳人到生态效率的评价中, 实现了将 城市生态效率从弱可持续性到强可持续性研究范式的转变。随着研究的深人, 学者们在丰富和完善原有生态 效率评价指标的同时,研究的对象也逐渐从省际、大中型城市以及城市群转向了更加微观的县域。在县域的 生态效率研究方面, 任宇飞和方创琳 ${ }^{[24]}$ 利用 DEA 模型评价了京津冀县域生态效率, 但是经济效益的产出指 标 GDP 和工业总产值二者有重叠部分, 而且难以评价除工业以外的其他产业; 刘海龙等 ${ }^{[25]}$ 构建耕地生态效 率指标体系, 分析了某特困区县域耕地生态效率和影响因素, 为县域农业生态建设提供了参考, 但并未涉及县 域其他产业; 周俊俊等 ${ }^{[26]}$ 运用热力学范畴中的扩展㶲分析方法, 较好地研究了宁南山区 3 县的生态效率驱动 机制及造成生态退化差异性的原因。

综上所述, 已有生态效率相关的研究对生态环境保护、区域发展以及行业和企业的绿色发展都具有很好 的参考价值。然而, 当前聚焦在县域生态效率评价方面的研究才刚刚兴起, 而且现有的研究中经济效益方面 的期望产出指标通常只局限地选取 GDP, 这种假设各地区具有统一的产出目标的评价方式,未考虑到不同县 域经济发展的特色, 未针对县域发展的不同导向对其生态效率进行差异化评价,进而无法突出重点、发挥优 势、形成特色。目前, 虽然县域生态效率评价的数据收集难度较大,且数据质量参差不齐, 但是基于不同发展 导向下各县域生态效率的差异化评价研究具有重要的学术意义和应用价值。因此,本研究以江苏省县域单元 数据为样本, 在期望产出中, 结合生态问题的特征加人了建成区绿化覆盖面积以及其他经济产出指标, 并且将 传统文献中 GDP 总量细分为一产、二产、三产的增加值, 以此构建相应的评价体系, 并归纳了乡村振兴、新型 工业和绿色经济三个发展导向, 以实现不同导向下县域生态效率的差异化评价,并从差异化的角度进一步探 寻其全要素生产率及其变动的主要原因, 从而为江苏省县域的生态发展和经济的高质量发展提供参考。

\section{1 研究方法与数据说明}

\section{1 改进的仁慈型交叉效率模型}

交叉效率评价方法利用自评、互评相结合的方式, 减轻了传统 DEA 模型过分依赖自评体系对决策单元进 行评价的弊端, 具有较强的公平性和全面性 ${ }^{[27]}$ 。但由于传统交叉效率最优权重可能并不唯一, 会出现多组不 同的交叉效率值而难以选择的问题,于是 Doyle 和 Green ${ }^{[28]}$ 提出了仁慈型交叉效率模型。鉴于江苏省县域是 在中央以及省市各级政府的统一领导部署下,且各区域间在经济发展与生态建设上都具有一定的合作关系， 符合仁慈型交叉效率评价的思想, 即在相互合作的情形下, 最大化被评价决策单元效率的同时,选择使其他决 策单元的综合效率值最大的最优权重组合, 从而达成共赢。同时, 考虑到江苏省县域发展各具特色, 要想从多 维发展导向视角评价其生态效率, 需对传统的仁慈型交叉效率模型进行如下两个方面的调整: 1)仁慈型交叉 效率模型是单纯地从最大化平均效率出发来分配最优权重, 未考虑不同产出的权重之间的关联。为了有效对 比不同类型的产出, 需对生态效率评价中的产出权重进行定性约束, 即对产出权重 $\mu$ 进行约束, 例如: 欲表示 产出 $p$ 的重要程度不低于产出 $q$, 则添加约束 $\alpha_{p} \mu p \geqslant \beta_{q} \mu q(p, q=1,2 \cdots s, p \neq q), \alpha_{p}$ 和 $\beta_{q}$ 均为专家给出的经验 常数; (2)仁慈型交叉效率模型的等式约束使自身效率 $E_{d d}$ 不得出现任何下降的情况下, 来最大化其他决策单元 效率, 约束性过强, 会导致部分单元出现无可行解的情况, 所以需要将等式约束放松, 为尽可能使自身效率 $E_{d d}$ 最大的同时能有最优可行解, 考虑放松到 0.99 倍的 $E_{d d}$ 。

基于上述分析,假设有 $n$ 个 DMUs, 每个 $\operatorname{DMU}_{j}(j=1,2, \cdots n)$ 都有 $m$ 种不同的投人变量和 $s$ 种不同的产出 变量, 即第 $j$ 个决策单元 $\mathrm{DMU}_{j}$ 的投人与产出变量分别为 $X_{j}\left(x_{1 j}, x_{2 j}, \cdots, x_{m j}\right)$ 和 $Y_{j}\left(y_{1 j}, y_{2 j}, \cdots, y_{s j}\right)$, 具体模型 如下: 


$$
\begin{aligned}
E_{d j}^{\max } & =\max \sum_{r=1}^{m} \mu_{r d} y_{r j} \\
\text { s.t. } & \sum_{i=1}^{m} v_{i d} x_{i j}=1, \\
& \sum_{r=1}^{s} \mu_{r d} y_{r d}-0.99 \cdot E_{d d} \cdot \sum_{i=1}^{m} v_{i d} x_{i d} \geqslant 0, \\
& \sum_{r=1}^{s} \mu_{r d} y_{r j}-\sum_{i=1}^{m} v_{i d} x_{i j} \leqslant 0, j=1,2, \cdots, n, \\
& \sum_{p=1}^{l} \alpha_{p} \mu_{\mathrm{p}} \geqslant \sum_{q=1}^{k} \beta_{q} \mu_{q}, l=1,2 \cdots, s_{1} ; k=1,2 \cdots, s_{2} ; l \neq k, \\
& \mu_{r d}, v_{i d} \geqslant 0, r=1,2, \cdots, s, i=1,2, \cdots, m,
\end{aligned}
$$

式中, $\omega_{i d}(i=1,2, \cdots, m)$ 和 $\mu_{r d}(r=1,2, \cdots, s)$ 分别代表投人变量 $x_{i j}$ 和产出变量 $y_{i j}$ 的权重, $E_{d d}$ 可通过 CCR 模 型求解。模型 (1) 是在保证所有决策单元效率都不超过 1 且自评效率 $E_{d d}$ 不小于 0.99 倍的前提下, 分配权重 使得能够最大化其他决策单元效率的决策方案。模型 (1) 中最优目标值 $E_{d j}^{\max }$ 被称为 $\mathrm{DMU}_{\mathrm{d}}$ 对 $D \mathrm{DU}_{\mathrm{j}}$ 的最大交 叉效率评价,解得所有最大交叉效率 $E_{d j}^{\max }(d, j=1,2, \cdots, n)$ 后可构成最大交叉效率矩阵如下:

$$
E^{\max }=\left(\begin{array}{cccc}
E_{11}^{\max } & E_{12}^{\max } & \cdots & E_{1 n}^{\max } \\
E_{21}^{\max } & E_{22}^{\max } & \cdots & E_{2 n}^{\max } \\
\vdots & \vdots & \vdots & \vdots \\
E_{n 1}^{\max } & E_{n 2}^{\max } & \cdots & E_{n n}^{\max }
\end{array}\right)
$$

对(2)中每列元素求平均, 则得到 $\operatorname{DMU}_{j}(j=1,2, \cdots, n)$ 的最大平均交叉效率, 即:

$$
\bar{E}_{j}^{\max }=\frac{1}{n} \sum_{d=1}^{n} E_{d j}^{\max }
$$

改进后的仁慈型交叉效率可以对生态效率的产出进行权重约束,并且继承了仁慈型交叉效率的基本思 想, 从共赢的视角出发,将江苏省视作一个区域整体并希望下辖县域的生态效率越大越好,各县域作为区域内 个体, 在保持自身生态效率达到最大化的同时, 也希望其他县域生态效率最优, 从而提高区域内的整体生态 效率。

\subsection{Malmquist 指数}

Färe 等 ${ }^{[29]}$ 基于 DEA 模型提出了可以评价多时期效率变动情况的 DEA-Malmquist 指数,并将效率变动的

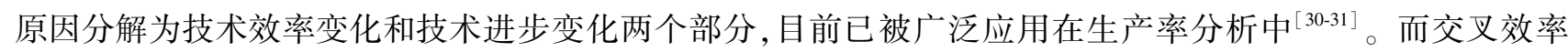
模型是从静态角度测度县域的生态效率, 无法识别各个县域跨时期的效率变动情况和变动原因, 为更深人探 讨县域生态效率的动态变化情况, 从而更好地为县域生态文明建设和绿色发展提供决策参考,故采用基于 DEA-Malmquist 指数模型计算全要素生产率 (Total Factor Productivity, 简称为 TFP) 指数并将其分解, 公式 如下:

$$
\mathrm{TFP}=\left[\frac{D^{t}\left(x^{t+1}, y^{t+1}\right)}{D^{t}\left(x^{t}, y^{t}\right)} \times \frac{D^{t+1}\left(x^{t+1}, y^{t+1}\right)}{D^{t+1}\left(x^{t}, y^{t}\right)}\right]^{\frac{1}{2}}=\underbrace{\frac{D^{t+1}\left(x^{t+1}, y^{t+1}\right)}{D^{t}\left(x^{t}, y^{t}\right)}}_{\text {EC }} \times \underbrace{\left[\frac{D^{t}\left(x^{t}, y^{t}\right)}{D^{t+1}\left(x^{t}, y^{t}\right)} \cdot \frac{D^{t}\left(x^{t+1}, y^{t+1}\right)}{D^{t+1}\left(x^{t+1}, y^{t+1}\right)}\right]^{1 / 2}}_{\text {TC }}
$$

式中, $\left(x^{t}, y^{t}\right)$ 和 $\left(x^{t+1}, y^{t+1}\right)$ 分别表示在 $t$ 和 $t+1$ 时期的投人和产出组合,TFP 表示全要素生产率指数, EC 表示 技术效率变化指数, TC 表示技术进步变化指数。当 $\mathrm{TFP}>1$ 时, 表示全要素生产率提高; $\mathrm{TFP}=1$ 时, 表示全要 素生产率不变; $\mathrm{TFP}<1$ 时,表示全要素生产率降低。当 $\mathrm{EC}>1$ 时,表示技术效率提高 $; \mathrm{EC}=1$ 时,表示技术效率 不变 $; \mathrm{EC}<1$ 时,表示技术效率降低。当 $\mathrm{TC}>1$ 时, 表示技术进步 $; \mathrm{TC}=1$ 时, 表示技术保持不变 $; \mathrm{TC}<1$ 时, 表示 技术退步。 


\section{3 评价指标选取及定性约束设置}

\subsection{1 评价指标选取}

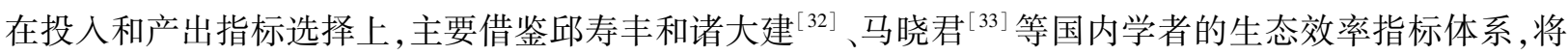
投人指标分为非资源投人和资源投人。其中,非资源投入包括资金消耗和劳动力消耗;资源投入包括能源消 耗和土地消耗。产出指标中, 将经济与环境保护作为期望产出, 环境污染则作为非期望产出。具体而言, 县域 生态效率投人产出关系如图 1 所示。

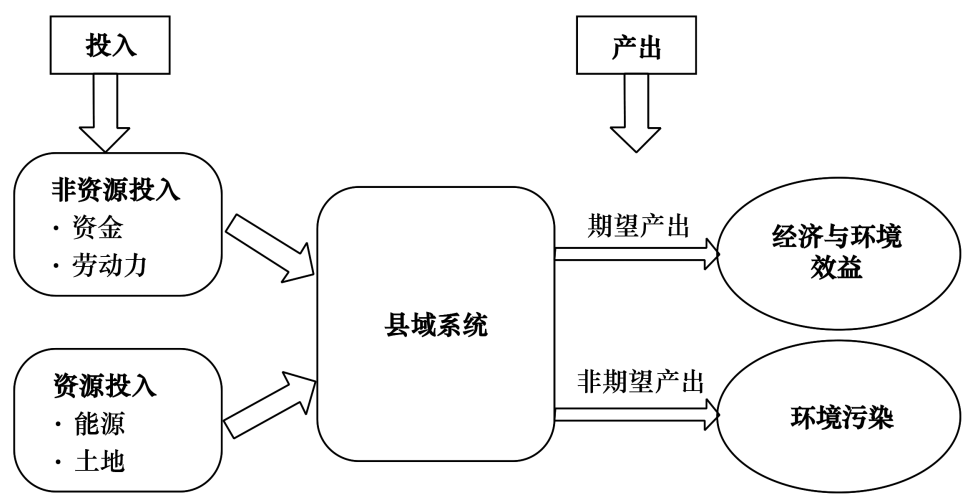

图 1 县域生态效率投入产出关系图

Fig.1 County eco-efficiency input-output relation diagram

在非资源投人中,资金投人用社会固定资产投资来衡量, 反映了社会建造和购置固定资产的货币投资总 量; 劳动力投人用该城市从业人员数量来衡量。资源投人中, 能源投入用全年用电量作为衡量指标; 土地投人 用建成区面积来衡量, 反映城市实际建设用地的范围。

在产出指标上,环境污染在生产过程中只能尽可能减少但不可避免,故作为非期望产出,计算时将其取倒 数转化为期望产出处理。在期望产出中, 将 GDP 总量细分为一产、二产、三产的增加值等经济收益指标, 并加 人了建成区绿化覆盖面积以衡量县域绿化环境。

\subsection{2 定性约束设置}

根据国民经济的三大产业划分,可以将城市的产业类型分为三类,即第一产业、第二产业、第三产业,而县 域经济作为国民经济的基本单元,其发展也主要围绕这三大产业展开。同时,不同县域的产业结构还存在着 一定的差异性。因此, 以三大产业为分类核心,结合绿色发展新理念中节约资源和保护环境的基本要求,对生 态效率评价中的期望产出和环境污染进行分类约束,将县域绿色发展模式按照产业不同分为三类。一是乡村 振兴导向 (Rural Revitalization Orientation, 简称为 RRO), 实施乡村振兴战略,优先发展农业农村, 坚持城乡融 合发展,促进农业产值和农民增收,所以采用第一产业增加值 $\left(y_{1}\right)$ 和农村常住居民可支配收人 $\left(y_{2}\right)$ 可以分别 反映一定时期内第一产业的产值和农民收人情况。二是新型工业化导向 ( New Industrial Orientation，简称为 $\mathrm{NIO})$, 此类县域工业较为发达,不同于高能耗、高污染的传统工业化,其主要侧重于发展知识形态下的工业 化,利用信息化、智能化等大力发展科技含量高、效益好的工业,所以采用第二产业增加值 $\left(y_{3}\right)$ 能够衡量一定 时期内第二产业的产值,规上工业利润 $\left(y_{4}\right)$ 则可以反映工业企业的效益。三是绿色经济导向 (Green Economy Orientation,简称为 GEO), 该类县域注重发展低能耗、低污染的第三产业,注重生态环境保护和城市生态建 设, 严格制约环境污染, 所以第三产业增加值 $\left(y_{5}\right)$ 可以代表一定时期内第三产业产值的增长情况, 建成区绿 化覆盖面积 $\left(y_{6}\right)$ 作为补充反映了县域的生态环境建设情况,环境污染指标 $y_{7} 、 y_{8} 、 y_{9}$ 则可以综合反映绿色发展 过程中对于污染物的控制。根据以上 3 种导向, 将产出指标分为三类, 分别为 $\left\{y_{1}, y_{2}\right\} 、\left\{y_{3}, y_{4}\right\} 、\left\{y_{5}, y_{6}, y_{7}\right.$, $\left.y_{8}, y_{9}\right\}$ 。以乡村振兴导向为例, 因为是注重农业农村的发展并控制污染, 所以农业产出指标 $y_{1}$ 和 $y_{2}$ 的权重最 大, 且分别大于第三产业和环境污染的指标集合 $\left\{y_{5}, y_{6}, y_{7}, y_{8}, y_{9}\right\}$, 代表工业经济产出指标的 $\left\{y_{3}, y_{4}\right\}$ 权重最 
低, 因此在乡村振兴导向下添加产出权重附加约束为 $\mu_{1 d}, \mu_{2 d} \geqslant \mu_{5 d}+\mu_{6 d}+\mu_{7 d}+\mu_{8 d}+\mu_{9 d} ; \mu_{5 d}, \mu_{6 d}, \mu_{7 d}, \mu_{8 d}, \mu_{9 d}$ $\geqslant \mu_{3 d}+\mu_{4 d}$, 生态效率评价代理变量及定性约束设置如表 1 所示。

由于 2015 年党的十八届五中全会提出绿色发展新理念,而生态效率提高是绿色发展新常态下的必然要 求。因此,本文选取 2015-2017 年江苏省各地级市城市统计年鉴中的县域数据进行生态效率评价,共计 32 个县或县级市,其中因地区统计数据缺失不包括徐州、淮安、常州下辖县市, 而南京则无下辖县级市。

表 1 生态效率评价代理变量及定性约束设置

Table 1 Agent variables and qualitative constraints setting for eco-efficiency evaluation

\begin{tabular}{lllc}
\hline 指标 & 指标类别 & 代理变量 & 变量 \\
Index & Index category & Proxy variable & $x_{1}$ \\
\hline 投人指标 & 资金投人 & 全社会固定资产投资 & $x_{2}$ \\
Input index & 劳动力投人 & 从业人员 & $x_{3}$ \\
& 能源投人 & 全年用电量 & $x_{4}$ \\
土地投人 & 建成区面积 & $y_{1}$ \\
产出指标 & 期望产出 & 第一产业增加值 & $y_{2}$ \\
Output index & 农村常住居民可支配收人 & $y_{3}$ \\
& & 第二产业增加值 & $y_{4}$ \\
& & 规上工业利润 & $y_{5}$ \\
& & 第三产业增加值 & $y_{6}$ \\
& 建成区绿化覆盖面积 & $y_{7}$ \\
& 工业废水排放量 & $y_{8}$ \\
& 工期望产出 & 工业二氧化硫排放量 & $y_{9}$ \\
& 工业烟 $($ 粉 $)$ 尘排放量 & $y_{1}, y_{2} \geqslant\left\{y_{5}, y_{6}, y_{7}, y_{8}, y_{9}\right\} ; y_{5}, y_{6}, y_{7}, y_{8}, y_{9} \geqslant\left\{y_{3}, y_{4}\right\}$
\end{tabular}

RRO: 乡村振兴导向 Rural Revitalization Orientation; NIO: 新型工业导向 New Industrial Orientation; GEO: 绿色经济导向 Green Economy Orientation

\section{2 实证结果分析}

\section{1 生态效率静态分析}

利用 MATLAB R2016a 软件,按照表 1 中的投人产出指标, 分别编写了改进的仁慈型交叉效率模型在原始 状态下和 3 种发展导向下的程序, 测算了江苏省 32 个县域 2015-2017 年的生态效率, 主要结果如图 2 和表 2 所示(保留四位小数)。

2.1.1 江苏省分地区县域生态效率比较分析

图 2 反映的是在无约束条件 (即不考虑县域发展导向差异) 以及 3 种不同发展导向下江苏省三大地区县 域历年生态效率的情况。在无约束条件下, 江苏省三大地区的县域生态效率均保持在 0.9700 以上,且苏南、 苏中、苏北三大地区生态效率差距较小, 表明江苏省三大地区对生态资源的利用已基本处在同一水平。然而, 事实是否真的如此呢? 从 3 种发展导向来看, 在考虑县域从属乡村振兴或新型工业发展导向时, 三大地区县 域的生态效率还是存在一定差异的,其中新型工业发展导向下的生态效率最低,类内差异最为明显,且苏北地 区降幅最大并呈现连跌态势。在绿色经济发展导向下,所得的结果与无约束的结果较为一致,这是因为无约 束时所测度的生态效率本身就是从绿色发展目标出发的,因此二者无论是趋势还是区域差异都较为一致。以 上结果表明,考虑县域经济发展导向能够帮助各类县域从不同维度充分挖掘其生态效率的特征以及区域差 异。因此,有必要从差异化发展导向出发探寻县域的生态效率。

三大地区的县域在绿色经济导向下生态效率值较高, 这与 Wang 和 Chen ${ }^{[34]}$ 的结论一致,这是由于第三 

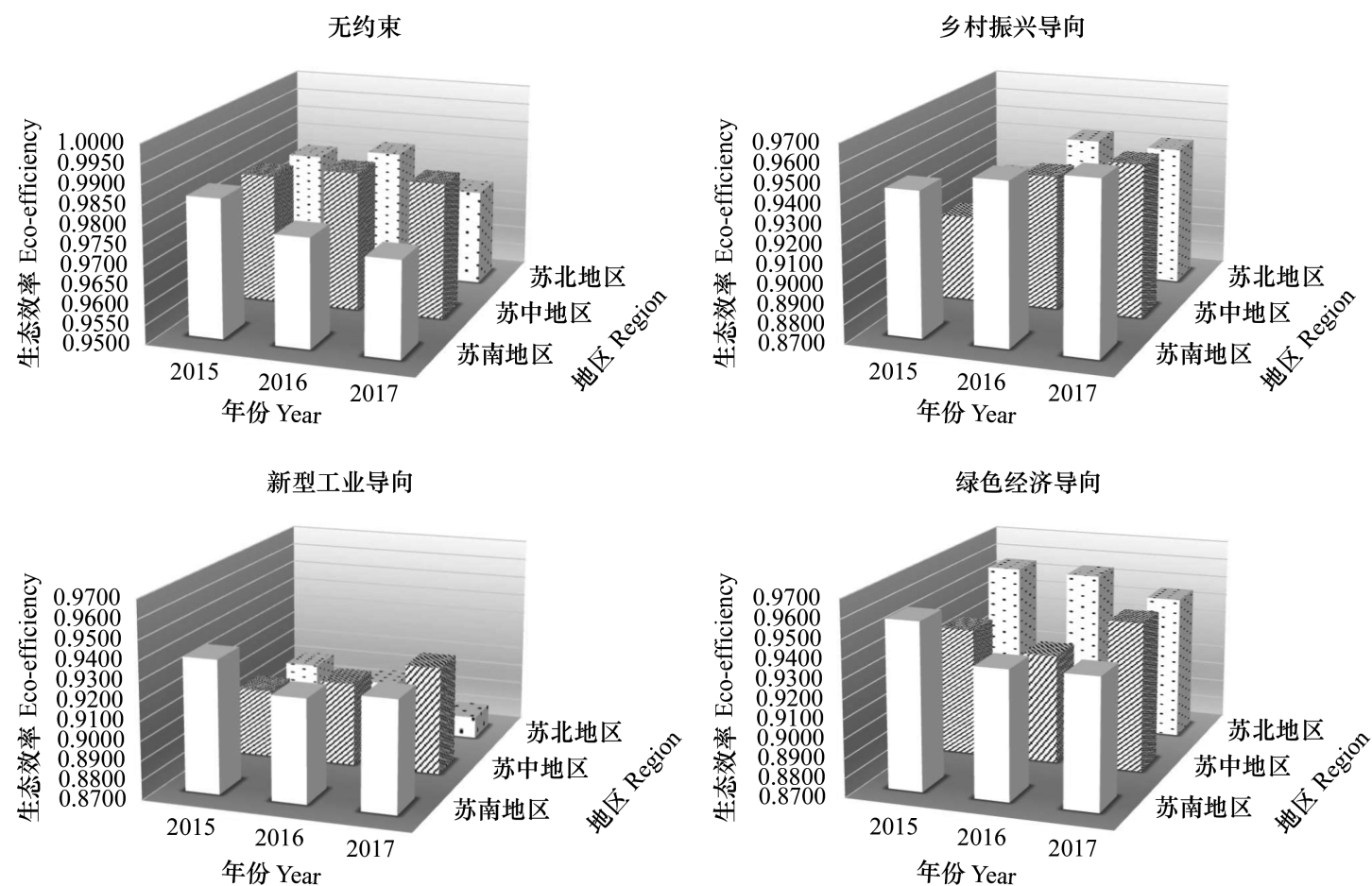

图 2 多维发展导向下江苏省分地区 2015-2017 县域生态效率

Fig.2 Eco-efficiency of counties in Jiangsu Province from 2015 to 2017 under multi-dimensional development viewpoint

产业涉及范围广泛, 不仅可以拓展经济发展空间,创造较高的经济附加值,而且具有资源消耗低和对环境影响 小的特点。在乡村振兴导向下,可以发现此类县域生态效率逐年上升,这主要是由于 2015 年以来江苏省进行 “三农”改革且发展成效卓越,农民不断增收,2017 年 32 个县域的人均农村居民可支配收人相比 2015 年上涨 了 $18.39 \%$ 。从时间维度来看, 2015 年苏南地区的生态效率值最高, 但苏南生态效率领先的趋势在 2016 年发 生转变,苏中地区和苏北地区的生态效率在 2016-2017 年间开始赶超苏南地区。

2.1.2 多维发展导向下县域生态效率测算结果及分析

表 2 为多维发展导向下江苏省各县域年均生态效率及排名情况。从表 2 的最后一列, 即绿色经济发展导 向生态效率排名来看, 扬中市生态效率最高, 这得益于扬中市长期以来以生态立市, 且其地处江中之岛, 四面 环水,生态脆弱,倒逼了绿色产业发展布局,促进了经济增长方式的转变,实现了经济与环境的协调发展。而 生态效率值最低的县域为张家港市, 但县域间效率值大小差距并不大, 所有城市生态效率值均在 0.8000 以 上, 其中效率达到 0.9500 以上的县域占了总数的 $40.6 \%$, 这反映出江苏省各县域生态效率都维持在较高的水 平, 没有出现两极分化, 这主要得益于江苏省经济全面开花, 同时江苏省是全国唯一一个所有地级市 GDP 均 进人全国百强的省份,也是人选 “县域经济 100 强 (2019) 榜单” 数目最多的省份 (占 26 席位)。然而,同一个 地级市下辖的县域效率值排名并不接近, 甚至有的差异很大, 如镇江市下辖的扬中市和丹阳市排名相差 28 位, 这说明在同一地级市行政区下的各县域生态效率的辐射效应不足,生态效率高的县域并不能够有效带动 周边地区,需加强高效率地区对周边的辐射带动作用,这与任宇飞 ${ }^{[24]}$ 测算的京津冀城市群县域生态效率结论 类似。与无约束的结果对比可知, 在绿色经济导向下, 生态效率值下降幅度最小, 下降最大的泰兴市生态效率 值降低了 0.0987 , 阜宁县和常熟市的生态效率值较为反常地大于在无约束下的效率值, 这是由于在绿色经济 导向下,交叉效率中某些他评的效率值增大最终导致最后取平均值后效率值增加。

在乡村振兴导向下,生态效率最高的宝应县为 0.9988 ,最低的泰兴市为 0.8539 。与无约束条件下相比, 在 排名上泰兴市和响水县的变化幅度较大, 分别退步了 15 和 14 个位次。在新型工业导向下,与无约束条件下 
相比, 部分县域的生态效率值下降幅度较为明显, 特别是响水县的生态效率值下降至 0.8000 以下; 而在排名 上下降较大的有兴化市、响水县和射阳县,三者的排名均退步 15 位以上,而阜宁县则进步了 16 位。从表 2 还 可知,全省县域均值在绿色经济导向下效率值最大,而在新型工业导向下效率值最小,这再次反映了发展绿色 且经济的第三产业更具有经济和环境的双重效益,而工业虽然经济产值较大,但其高投人和对环境的污染造 成了生态效率相对较低,这一结论也与实际相符。

表 2 多维发展导向下 2015-2017 年 32 个县域年均生态效率测算结果

Table 2 Results of annual average ecological efficiency of 32 counties from 2015 to 2017 under the guidance of multidimensional development

\begin{tabular}{|c|c|c|c|c|c|c|c|c|c|}
\hline \multirow{2}{*}{$\begin{array}{l}\text { 地区 } \\
\text { Region }\end{array}$} & \multirow{2}{*}{$\begin{array}{c}\text { 县市 } \\
\text { County }\end{array}$} & \multicolumn{2}{|c|}{$\begin{array}{c}\text { 无约束 } \\
\text { Unconstrained }\end{array}$} & \multicolumn{2}{|c|}{$\begin{array}{c}\text { 乡村振兴导向 } \\
\text { RRO }\end{array}$} & \multicolumn{2}{|c|}{$\begin{array}{c}\text { 新型工业导向 } \\
\text { NIO }\end{array}$} & \multicolumn{2}{|c|}{$\begin{array}{c}\text { 绿色经济导向 } \\
\text { GEO }\end{array}$} \\
\hline & & 效率 & 排名 & 效率 & 排名 & 效率 & 排名 & 效率 & 排名 \\
\hline 苏南 & 江阴市 & 0.9806 & 23 & 0.9559 & 12 & 0.9301 & 15 & 0.9462 & 16 \\
\hline \multirow[t]{8}{*}{ Southern Jiangsu Province } & 宜兴市 & 0.9900 & 9 & 0.9704 & 6 & 0.9778 & 4 & 0.9848 & 5 \\
\hline & 常熟市 & 0.9965 & 3 & 0.9715 & 4 & 0.9840 & 2 & 0.9968 & 3 \\
\hline & 张家港 & 0.9485 & 31 & 0.8911 & 29 & 0.7889 & 31 & 0.8455 & 32 \\
\hline & 昆山市 & 0.9912 & 8 & 0.9694 & 7 & 0.9617 & 7 & 0.9232 & 25 \\
\hline & 太仓市 & 0.9866 & 13 & 0.9568 & 11 & 0.9317 & 14 & 0.9550 & 13 \\
\hline & 丹阳市 & 0.9611 & 30 & 0.9344 & 19 & 0.8851 & 23 & 0.8985 & 29 \\
\hline & 扬中市 & 0.9995 & 2 & 0.9938 & 2 & 0.9995 & 1 & 0.9995 & 1 \\
\hline & 句容市 & 0.9616 & 29 & 0.9271 & 22 & 0.9094 & 18 & 0.9471 & 15 \\
\hline 地区均值 Regional mean & & 0.9795 & & 0.9523 & & 0.9298 & & 0.9441 & \\
\hline 苏中 ～～～～～～ & 海安县 & 0.9700 & 26 & 0.9061 & 27 & 0.8860 & 22 & 0.9158 & 26 \\
\hline \multirow[t]{10}{*}{ Central Jiangsu Province } & 如东县 & 0.9833 & 19 & 0.9270 & 23 & 0.8574 & 27 & 0.9077 & 27 \\
\hline & 启东市 & 0.9918 & 7 & 0.9693 & 8 & 0.9398 & 13 & 0.9492 & 14 \\
\hline & 如者市 & 0.9622 & 28 & 0.9211 & 24 & 0.8911 & 21 & 0.9370 & 22 \\
\hline & 海门市 & 0.9937 & 5 & 0.9569 & 10 & 0.9676 & 6 & 0.9016 & 28 \\
\hline & 宝应县 & 1.0000 & 1 & 0.9988 & 1 & 0.9717 & 5 & 0.9990 & 2 \\
\hline & 仪征市 & 0.9828 & 20 & 0.8975 & 28 & 0.9476 & 10 & 0.9782 & 8 \\
\hline & 高邮市 & 0.9860 & 15 & 0.9604 & 9 & 0.8405 & 29 & 0.9356 & 23 \\
\hline & 兴化市 & 0.9927 & 6 & 0.9533 & 14 & 0.8578 & 26 & 0.9440 & 18 \\
\hline & 靖江市 & 0.9861 & 14 & 0.9364 & 18 & 0.9816 & 3 & 0.9575 & 12 \\
\hline & 泰兴市 & 0.9843 & 17 & 0.8539 & 32 & 0.9197 & 16 & 0.8856 & 31 \\
\hline 地区均值 Regional mean & & 0.9848 & & 0.9346 & & 0.9146 & & 0.9374 & \\
\hline 苏北 ～～～～ & 东海县 & 0.9826 & 21 & 0.9328 & 21 & 0.9084 & 19 & 0.9436 & 19 \\
\hline \multirow[t]{11}{*}{ Northern Jiangsu Province } & 灌云县 & 0.9896 & 10 & 0.9715 & 4 & 0.9452 & 11 & 0.9650 & 10 \\
\hline & 灌南县 & 0.9803 & 24 & 0.9467 & 17 & 0.8515 & 28 & 0.9311 & 24 \\
\hline & 响水县 & 0.9867 & 12 & 0.9122 & 26 & 0.7833 & 32 & 0.9405 & 20 \\
\hline & 滨海县 & 0.9668 & 27 & 0.8906 & 30 & 0.8694 & 24 & 0.9626 & 11 \\
\hline & 阜宁县 & 0.9796 & 25 & 0.9487 & 16 & 0.9485 & 9 & 0.9801 & 7 \\
\hline & 射阳县 & 0.9949 & 4 & 0.9797 & 3 & 0.9013 & 20 & 0.9454 & 17 \\
\hline & 建湖县 & 0.9858 & 16 & 0.9187 & 25 & 0.9192 & 17 & 0.9852 & 4 \\
\hline & 东台市 & 0.9842 & 18 & 0.9511 & 15 & 0.8579 & 25 & 0.9385 & 21 \\
\hline & 沭阳市 & 0.9818 & 22 & 0.9333 & 20 & 0.9447 & 12 & 0.9651 & 9 \\
\hline & 泗阳市 & 0.9364 & 32 & 0.8905 & 31 & 0.8359 & 30 & 0.8900 & 30 \\
\hline & 泗洪县 & 0.9896 & 10 & 0.9536 & 13 & 0.9510 & 8 & 0.9815 & 6 \\
\hline 地区均值 Regional mean & & 0.9799 & & 0.9358 & & 0.8930 & & 0.9524 & \\
\hline 省均值 Provincial mean & & 0.9815 & & 0.9400 & & 0.9108 & & 0.9449 & \\
\hline
\end{tabular}

由于在 3 种发展导向下,各县域的生态效率排名呈现不尽相同的波动, 部分县域波动甚至超过 10 位以 上,因此在表 2 基础上按照排名最优将县域分为三类 (表 3), 从而更好地区分各县域在哪个发展导向下同其 他县域相比表现得相对最优。从表 3 中可以看出, 乡村振兴类县域的数目最多有 14 席, 说明绝大多数县域在 
乡村振兴导向下的排名表现得相对最优,在新型工业导向下排名相对最优的县域仅有 8 席,并且从前文中可 知在新型工业导向下生态效率值还最小,因此江苏省绝大多数的县域需要重点改善第二产业的生态效率。此 外,对于在某一个导向下排名相对领先, 而在其他导向下排名落后的县域(例如昆山市、海门市在乡村振兴导 向下排名都较为理想, 而在绿色经济导向下排名明显落后), 应该着力改善第三产业的生态效率,补齐在绿色 经济导向下生态效率相对落后的短板; 对于张家港市、泗阳市等在 3 种导向下排名都相对靠后的县域,则应对 照效率领先的县域,全面改善第一产业、第二产业、第三产业的生态效率。

2.2 生态效率动态分析

基于江苏省县域 2015-2017 年面板数据,利用 DEA-Malmquist 指数模型对其生态效率进行动态实证分 析, 使用 Deap2.1 软件计算全要素生产率指数并对其进行分解, 分时期的县域生态全要素生产率指数增减情 况如图 3 所示。

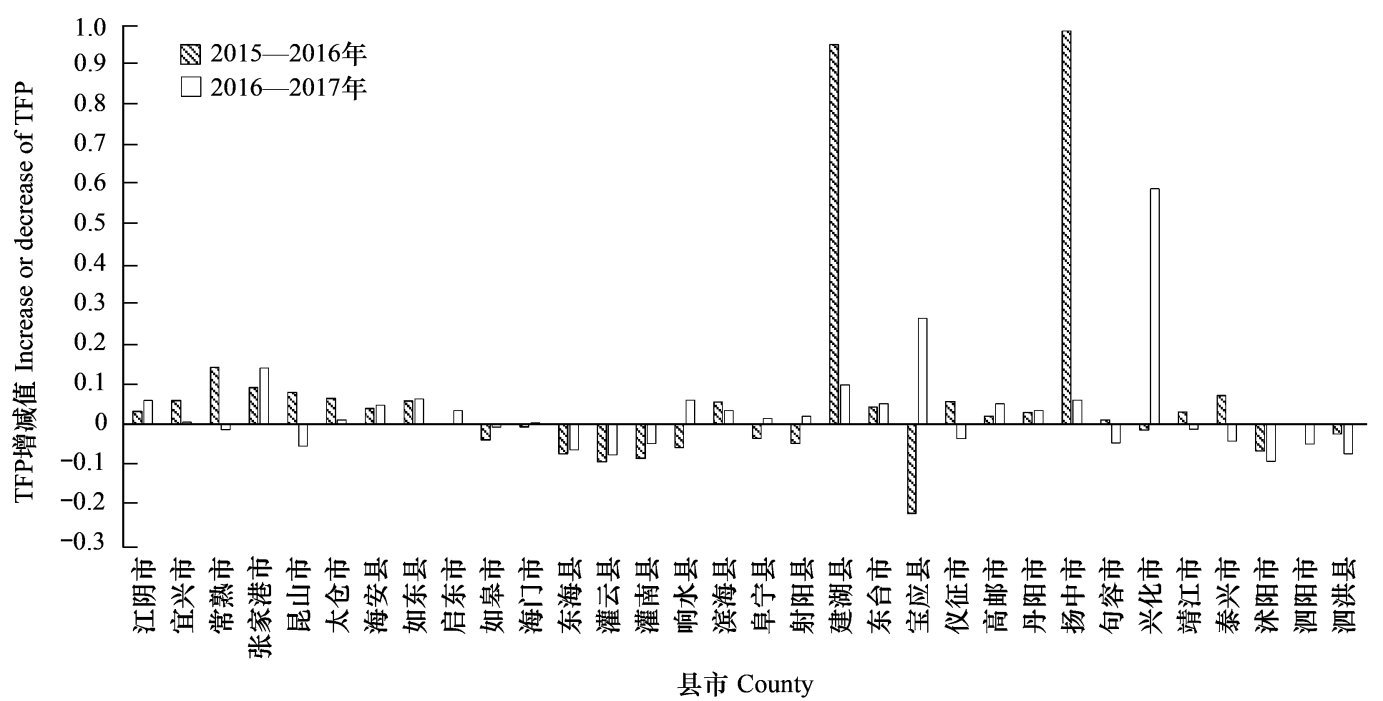

图 3 分时期的江苏省县域生态全要素生产率指数增减图

Fig.3 Increasing and decreasing indexes of the total factor productivityof the county ecology in Jiangsu Province $\mathrm{TFP}$ : 全要素生产率 Total factor productivity

从图 3 可知,两个时期 TFP 同时增长的县域有 13 个, 分别为江阴市、宜兴市、张家港市、太仓市、海安县、 如东县、启东市、滨海县、建湖县、东台市、高邮市、丹阳市、扬中市; 两个时期 TFP 同时降低的有如臮市、东海 县、灌云县、灌南县、沭阳市、泗洪县等 6 个县域。比较同一县域不同时期的 TFP 变化,进步最为明显的有扬 中市和建湖县, 与上一时期相比, TFP 分别增长了 $98.6 \% 、 95.3 \%$, 通过对比这两个县域在不同时期的原始数 据, 发现扬中市和建湖县的 TFP 进步如此明显的原因是环境治理使得污染排放大幅减少。以工业 $\mathrm{SO}_{2}$ 排放 量为例,扬中市 2017 年的工业 $\mathrm{SO}_{2}$ 排放量同比上年减少 $79.2 \%$,建湖县 2016 年的工业 $\mathrm{SO}_{2}$ 排放量同比上年 减少 53.5\%。图 3 中,宝应县、兴化市和常熟市,同比上一时期 TFP 下降幅度均超过 10\%,其他县域两个时期 的 TFP 增减幅度都相近。在 2015-2016 年间的启东市、泗阳市, 以及在 2016-2017 年间的宜兴市、海门市， 由于 TFP 的增减值均小于或等于 0.005 , 所以图 3 中没有显示。根据计算结果还可知, 2015-2016 年和 2016-2017 年两个时期的 TFP 的几何均值分别为 1.045 和 1.025 , 说明江苏省县域生态效率在 2015-2017 年 间总体呈现上升态势。

表 4 的结果主要包括各县域生态全要素生产率指数及其分解,年均结果是取几何平均后所得。从全省来 看,生态全要素生产率指数的平均值为 1.035 ,增长率为 3.5\%, 说明 2015-2017 年间江苏省县域整体的生态 效率呈上升趋势, 经济增长模式正朝着绿色、集约的方向发展, 这与江苏省深化绿色发展和建设生态文明有直 接关系。尤其是党的十八大以来, 江苏省把资源要素集约和节约利用放在优先位置, 深人实施“两减六治三 
提升”行动,大力推进污染防治和节能减排工作,提升了生态资源投人转化为经济产出的效率。表 4 中,局部 县域全要素生产率具有显著差异,如最高的建湖县为 1.465 ,最低的灌云县为 0.914 。全要素生产率呈现正增 长的有 19 个, 占所有县域的 $59.4 \%$ 。

\section{表 3 多维发展导向下县域生态效率按照排名最优分类}

Table 3 The optimal classification of the ecological efficiency of counties under the guidance of multi-dimensional development

\begin{tabular}{ll}
\hline 类别 Category & 县市 County \\
\hline 乡村振兴类 RRO & 江阴市、张家港、昆山市、太仓市、丹阳市、如东县、启东市、宝应县、高邮市、兴化市、灌云县、灌南县、射阳县、东 \\
新型工业类 NIO & 台 \\
绿色经济类 GEO & 宜兴市、常熟市、扬中市、海安县、如者市、海门市、靖江市、泰兴市 \\
\hline
\end{tabular}

若不同导向下排名相同,则比较效率值大小;扬中市生态效率出现排名和大小皆相同,比较产业规模后纳人新型工业类

表 $42015-2017$ 年江苏省县域年均生态全要素生产率指数及其分解

Table 4 The annual average ecological total factor productivity index and its decomposition of county in Jiangsu Province during 2015 to 2017

\begin{tabular}{|c|c|c|c|c|c|c|c|}
\hline 县域 County & $\mathrm{EC}$ & $\mathrm{TC}$ & TFP & 县域 County & EC & $\mathrm{TC}$ & TFP \\
\hline 江阴市 & 1.000 & 1.045 & 1.045 & 海安县 & 1.018 & 1.025 & 1.044 \\
\hline 张家港市 & 1.000 & 1.116 & 1.116 & 如畠市 & 0.976 & 1.001 & 0.976 \\
\hline 昆山市 & 1.000 & 1.010 & 1.010 & 海门市 & 1.000 & 0.998 & 0.998 \\
\hline 太仓市 & 1.000 & 1.037 & 1.037 & 靖江市 & 1.000 & 1.008 & 1.008 \\
\hline 如东县 & 1.000 & 1.061 & 1.061 & 泰兴市 & 1.000 & 1.013 & 1.013 \\
\hline 启东市 & 1.000 & 1.017 & 1.017 & $\begin{array}{l}\text { 新型工业类均值 } \\
\text { Mean of NIO }\end{array}$ & 0.999 & 1.065 & 1.064 \\
\hline 宝应县 & 1.000 & 0.992 & 0.992 & 东海县 & 0.998 & 0.932 & 0.931 \\
\hline 高邮市 & 1.000 & 1.036 & 1.036 & 响水县 & 1.000 & 0.999 & 0.999 \\
\hline 丹阳市 & 0.988 & 1.045 & 1.032 & 滨海县 & 1.008 & 1.036 & 1.045 \\
\hline 灌云县 & 1.000 & 0.914 & 0.914 & 阜宁县 & 1.000 & 0.989 & 0.989 \\
\hline 灌南县 & 1.000 & 0.932 & 0.932 & 建湖县 & 1.016 & 1.442 & 1.465 \\
\hline 射阳县 & 1.000 & 0.985 & 0.985 & 仪征市 & 1.000 & 1.009 & 1.009 \\
\hline 东台市 & 1.000 & 1.047 & 1.047 & 句容市 & 0.989 & 0.992 & 0.981 \\
\hline 兴化市 & 1.000 & 1.252 & 1.252 & 沭阳市 & 1.000 & 0.920 & 0.920 \\
\hline $\begin{array}{l}\text { 乡村振兴类均值 } \\
\text { Mean of RRO }\end{array}$ & 0.999 & 1.032 & 1.031 & 泗阳市 & 0.969 & 1.007 & 0.976 \\
\hline 宜兴市 & 1.000 & 1.032 & 1.032 & 泗洪县 & 1.000 & 0.950 & 0.950 \\
\hline 常熟市 & 1.000 & 1.061 & 1.061 & $\begin{array}{l}\text { 绿色经济类均值 } \\
\text { Mean of GEO }\end{array}$ & 0.998 & 1.019 & 1.017 \\
\hline 扬中市 & 1.000 & 1.451 & 1.451 & $\begin{array}{l}\text { 全省均值 } \\
\text { Provincial mean }\end{array}$ & 0.999 & 1.036 & 1.035 \\
\hline
\end{tabular}

EC: 技术效率 Technical efficiency; TC: 技术进步 Technological progress; TFP: 全要素生产率 Total factor productivity

从分解的全省均值来看,技术效率变动指数年均下降 $0.001 \%$,其对 TFP 增长率的贡献率为 $-0.29 \%$,说明 技术效率变化率的下降总体上制约了全要素生产率指数 TFP 的增长率,表明江苏省县域利用绿色新技术的 能力有所减弱, 资源配置效率和资源的总量控制有待提高。技术进步指数年均增长 $3.6 \%$,其对 TFP 增长率的 贡献率为 $102.86 \%$, 在总体上促进了全要素生产率指数 TFP 的增长率, 表明技术进步变动指数是促进江苏省 生态全要素生产率指数增长的主导因素。具体到各个县域,有 24 个县域的技术效率变动指数等于 1 , 其余县 域的技术效率变动指数与 1 很接近, 但各个县域的技术进步 $\mathrm{TC}$ 值差距较大, 技术进步增长最快的是扬中市、 建湖县、兴化市, 分别增长了 $45.1 \% 、 44.2 \% 、 25.2 \%$, 超过均值 $18.96 \% 、 39.2 \% 、 20.8 \%$, 而技术退步的县域有 11 个,其中技术退步最大的为灌云县, 下降了 $8.6 \%$ 。从影响生态效率的增长因素来看, 技术进步是促进其增长 的主导因素, 而技术效率变动指数小于 1 ,则制约其增长。 
根据县域分类来看,不同发展导向下县域生态全要素生产率指数存在差异,乡村振兴类县域中 TFP 平均 为 1.032 , 并且 $\mathrm{TC}$ 平均为 1.032 , 说明这类县域的生态效率逐步得到改善, 技术进步是促进其进步的主导因 素。在新兴工业类县域中, $\mathrm{TC}$ 均值为 1.065 , 是唯一一类 $\mathrm{TC}$ 高于全省均值的县域,说明此类县域技术进步最 为迅速, 其中海安县的 EC 和 TC 均大于 1 , 说明该县的全要素生产率增长是受到了技术效率和技术进步的双 重驱动。在绿色经济类中 EC 和 TC 均大于 1 的县域有滨海县和建湖县,而东海县、句容市的 $\mathrm{EC}$ 和 TC 均小于 1 , 此类县域的 TC 均值为三类中最小, TC 小于 1 的县域占了 $60 \%$, 说明有六成的县域技术是退步的,因此此类 县域应加大科学技术投人, 鼓励创新, 充分发挥技术进步对生态效率的促进作用。此外, 在这三类县域中, EC 均值全部小于 1 , 全省县域的生态资源利用率和对资源的总量控制有待进一步加强。

\section{3 结论与启示}

本文基于 2015-2017 年江苏省 32 个县域的面板数据, 在多维发展导向视角下利用具有权重约束的改进 的交叉效率模型和 Malmquist 生产率指数对县域生态效率进行分析, 以期对推动江苏省以及我国其他地区生 态文明建设提供参考。具体而言, 主要结论与启示如下。

（1）从全省效率来看, 2015-2017 三年间江苏省县域生态效率总体水平较高,苏南、苏中、苏北县域生态 效率没有出现明显的两极分化, 但在不同发展导向下三大地区县域的生态效率还是存在一定差异, 苏北地区 县域在新型工业导向下效率下降最为明显。在同一地级市, 其下辖的县域生态效率排名差距大, 生态效率高 的县域难以起到带动周边的作用, 辐射效应不足。因此, 需要加强生态效率较高县域的辐射带动作用, 生态效 率领先的县域要利用自身资金、人才等优势来推动同周边县域的经济协调发展和生态环境共同治理,在同一 个地级市行政区内构建“一个中心,多个外围”或者“多个中心,多个外围”的辐射发展经济生态格局。

(2) 江苏省县域生态效率在不同发展导向下排名差异较大,排名最优分类主要集中在乡村振兴类和绿色 经济类。从平均水平上看, 生态效率值在绿色经济导向下最高, 乡村振兴导向下次之, 新型工业导向下最低。 因此, 各县域需根据实际分析不同产业生态效率的差异, 继续保持原来高效产业的生态效率, 并着重弥补低效 产业生态效率短板, 如昆山、海门、靖江等县市在新型工业导向下生态效率在全省排名领先, 而在绿色经济导 向下生态效率则相对落后, 故第三产业生态效率具有更大的提升空间。同时,针对江苏省第二产业、第三产业 比重大的情况, 江苏省县域需要因地制宜发展适宜当地生态的特色农业或经济作物, 使第一产业稳定发展, 在 此基础上着重改善第二产业生态效率。

(3) 从动态分析结果看, 各类不同发展导向以及江苏省整体的生态全要素生产率指数平均值大于 1 , 说明 江苏省整体和各类县域生态效率均呈现上升趋势, 技术进步指数的增长是促进江苏省县域生态全要素生产率 指数增长的主导因素, 而绝大多数县域的技术效率变动指数保持不变或呈现衰退现象, 表明江苏省县域利用 生态技术效率的能力没有得到提升。分类别来看, 新型工业类县域的技术进步变动指数最高, 而绿色经济类 县域最低。因此, 想要提高生态效率的增长率需要从两个方面人手, 首先要加大科研投人力度, 特别是针对技 术进步变动指数小于 1 的县域, 需要拓宽科研经费的来源, 利用科技带动生产力。其次, 全省县域都应合理配 置县域生态资源, 控制资源总量, 从而促进生态全要素生产率的提升。

本文从差异化发展导向出发, 评价了江苏省县域的生态效率, 对江苏省县域选择重点发展产业、实施产业 结构优化和稳步推进绿色发展均具有一定的参考意义。然而, 需要指出的是, 由于数据限制, 研究中的评价对 象未能涵盖江苏省的所有县域, 也未采用其他省份的数据进行对比。在后续的研究中, 可进一步扩大研究范 围,选择我国东部、中部、西部等地区的县域进行对比分析,并细化各个发展导向下的指标体系,深人分析我国 县域生态效率的区域差异性。此外, 在各县域生态效率分析的基础上, 探寻各县域的最优差异化发展路径有 待进一步研究。

\section{参考文献 ( References) :}

［1］黄勤, 曾元, 江琴. 中国推进生态文明建设的研究进展. 中国人口·资源与环境, 2015, 25(2): 111-120. 
[ 2 ] 龙亮军. 中国主要城市生态福利绩效评价研究——基于 PCA-DEA 方法和 Malmquist 指数的实证分析. 经济问题探索, 2019，(2): 69-79.

[ 3 ] 杨勇, 邓祥征. 中国城市生态效率时空演变及影响因素的区域差异. 地理科学, 2019, 39(7): 1111-1118.

[ 4 ] 尹科, 王如松, 周传斌, 梁菁. 国内外生态效率核算方法及其应用研究述评. 生态学报, 2012, 32(11): 3595-3605.

[ 5 ] Song M L, An Q X, Zhang W, Wang Z Y, Wu J. Environmental efficiency evaluation based on data envelopment analysis: a review. Renewable and Sustainable Energy Reviews, 2012, 16(7): 4465-4469.

[ 6 ] 曹俊文, 曾康. 低碳视角下长江经济带农业生态效率及影响因素研究. 生态经济, 2019, 35(8): 115-119, 127-127.

[ 7 ] 盖美, 展亚荣. 中国沿海省区海洋生态效率空间格局演化及影响因素分析. 地理科学, 2019, 39(4): 616-625.

[ 8 ] 陈荣文, 王美强, 李丹. 基于改进 SBM 模型的中国省际间生态效率研究. 科技管理研究, 2019, 39(6): 248-254.

[ 9 ] 王宝义, 张卫国. 中国农业生态效率的省际差异和影响因素——基于 1996 2015 年 31 个省份的面板数据分析. 中国农村经济, 2018, (1) : 46-62.

[10］刘钊. 基于三阶段 DEA 模型的中国区域绿色投资生态效率分析. 经济经纬, 2019，36(6)：17-24.

[11］盖美, 聂晨. 环渤海地区生态效率评价及空间演化规律. 自然资源学报, 2019, 34(1)：104-115.

[12] 彭薇, 熊科. 环境压力视角的广东省市域生态效率综合评价. 经济地理, 2018, 38(8) : 179-186.

[13］郑兵云, 杨宏丰. 基于生态足迹的中国省际旅游生态效率时空演化. 华东经济管理, 2020, 34(4) : 79-91.

[14] 刘存斌, 陈兴鹏, 逯承鹏, 许新宇, 李恒吉. 基于 DEA 交叉模型的西北干旱地区城市效率评价一一以肃河西地区为例. 兰州大学学报: 自然科学版, 2012, 48(6): 32-36.

[15] Liu X L, Guo P B, Guo S F. Assessing the eco-efficiency of a circular economy system in China's coal mining areas: emergy and data envelopment analysis. Journal of Cleaner Production, 2019, 206: 1101-1109.

[16] Fan Y P, Bai B Y, Qiao Q, Kang P, Zhang Y, Guo J. Study on eco-efficiency of industrial parks in China based on data envelopment analysis. Journal of Environmental Management, 2017, 192: 107-115.

[17] Charmondusit K, Phatarachaisakul S, Prasertpong P. The quantitative eco-efficiency measurement for small and medium enterprise: a case study of wooden toy industry. Clean Technologies and Environmental Policy, 2014, 16(5) : 935-945.

[18] Stępień S, Czyżewski B, Sapa A, Borychowski M, Poczta W, Poczta-Wajda A. Eco-efficiency of small-scale farming in Poland and its institutional drivers. Journal of Cleaner Production, 2021, 279: 123721.

[19］任宇飞, 方创琳, 淢雪芹. 中国东部沿海地区四大城市群生态效率评价. 地理学报, 2017, 72(11): 2047-2063.

[20] 黄和平, 李亚丽, 王智鹏. 基于 Super-SBM 模型的中国省域城市工业用地生态效率时空演变及影响因素研究. 生态学报, 2020, 40(1): 100-111.

[21] 马勇, 童旳, 任洁. 多源遥感数据支持下的县域尺度生态效率测算及稳健性检验——长江中游城市群为例. 自然资源学报, 2019,34 (6) : 1196-1208.

[22］常新锋, 管金金. 新型城镇化进程中长三角城市群生态效率的时空演变及影响因素. 经济地理, 2020, 40(3): 185-195.

[23] Bian J, Zhang Y, Shuai C Y, Shen L Y, Ren H, Wang Y P. Have cities effectively improved ecological well-being performance? Empirical analysis of 278 Chinese cities. Journal of Cleaner Production, 2020, 245: 118913.

[24] 任宇飞, 方创琳. 京津冀城市群县域尺度生态效率评价及空间格局分析. 地理科学进展, 2017, 36(1) : 87-98.

[25] 刘海龙, 王虎, 谢亚林, 李曼, 石培基. 集中连片特困区耕地生态效率的时空演变特征及影响因素分析一一以吕梁山区为例. 水土保持 研究, 2020, 27(2): 323-329.

[26] 周俊俊, 娤新刚, 杨美玲, 肖成权, 贾红丽. 县域生态效率驱动机制对比一一宁南山区 3 县为例. 应用生态学报, 2020, 31 (1)： 239-248.

[27] 梁樑, 吴杰. 数据包络分析 (DEA) 的交叉效率研究进展与展望. 中国科学技术大学学报, 2013, 43(11): 941-947.

[28] Doyle J R, Green R H. Cross-evaluation in dea: improving discrimination among dmus. INFOR: Information Systems and Operational Research, 1995, 33(3): 205-222.

[29] Färe R, Grosskopf S, Lindgren B, Roos P. Productivity changes in Swedish pharamacies 1980-1989: a non-parametric Malmquist approach. Journal of Productivity Analysis, 1992, 3(1): 85-101.

[30］王应明, 蓝以信. 基于双前沿面数据包络分析的循环全局 Malmquist 指数. 中国管理科学, 2015, 23(11): 46-55.

[31] 蓝以信, 王旭, 王应明. 区间型产出下的 DEA-Malmquist 生产率指数及其应用研究. 系统科学与数学, 2017, 37(6): 1494-1508.

[32] 邱寿丰, 诸大建. 我国生态效率指标设计及其应用. 科学管理研究, 2007, 25(1): 20-24.

[33] 马晓君, 李显东, 王常欣, 于洲博. 约束条件下中国循环经济发展中的生态效率一一基于优化的超效率 SBM-Malmquist-Tobit 模型. 中国 环境科学, 2018, 38(9): 3584-3593.

[34] Wang Y, Chen X Y. Natural resource endowment and ecological efficiency in China: revisiting resource curse in the context of ecological efficiency. Resources Policy, 2020, 66: 101610. 